\title{
PENSAMIENTO NACIONALISTA-TERRITORIALIZADO Y PERCEPCIÓN DE "DES-UBICAMIENTO" DEL INMIGRANTE: EL CAMINO HOSTIL DE LAS CONSTRUCCIONES DE IDENTIDADES CHILENAS EN LA CONVIVENCIA ESCOLAR ${ }^{1}$
}

\author{
Pablo Roessler ${ }^{2}$
}

RESUMEN

La presente investigación busca comprender cómo expresan su identidad nacional los adolescentes chilenos que se encuentran en contacto con pares de origen inmigrante. Considerando un contexto de inequidad y exclusión social para quienes migran y quienes reciben, se analizan las construcciones de identidades nacionales, junto con su plena vigencia actual e interacción histórica con los fenómenos migratorios. Por medio de técnicas de investigación cualitativas aplicadas entre 2016 y 2017 en seis establecimientos educacionales municipales de las comunas de Santiago y Quinta Normal, se evidenció un conjunto de discursos de las y los adolescentes chilenos acerca de su identidad nacional, que se forjan excluyentes y con baja/nula valoración hacia un otro-inmigrante. En dichos discursos resalta un pensamiento nacionalista-territorializado al momento de construir sujetos legítimos de derechos, no reconociendo entre ellos a sus pares de origen inmigrante, quienes son percibidos como portadores de fronteras cotidianas que los sitúan en una posición desterritorializada y de deudor a ojos de los nativos.

Conceptos clave: desterritorialización, fronteras cotidianas, identidad(es) nacional(es), pensamiento nacionalista-territorializado, sujetos de derecho.

\section{NATIONALIST-TERRITORIALIZED THINKING AND PERCEPTION OF THE "DE-LOCATION" OF THE IMMIGRANT: THE HOSTILE ROAD OF THE CONSTRUCTION OF CHILEAN IDENTITIES IN SCHOOL COEXISTENCE}

ABSTRACT

This investigation seeks to understand how Chilean adolescents, who who interact with immigrant peers, express their national identity. Considering contexts of inequality and social exclusion of immigrants and locals, this article analyzes the constructions of national identities, regarding both its current relevancy and historical interaction with the migration

1 El presente artículo se enmarca dentro de los resultados finales del proyecto de tesis para optar a grado de Magíster en Sociología en la P. Universidad Católica de Chile, titulado "Entre des-ubicamiento y aprendizajes: expresiones de identidades chilenas en adolescentes que conviven con pares inmigrantes en el espacio escolar". Se agradece el financiamiento del Centro de Estudios Interculturales e Indígenas (CIIR) FONDAP 15110006-CIIR, y a la Fundación Superación de la Pobreza por el apoyo otorgado en el marco del programa Tesis País.

2 Servicio Jesuita a Migrantes, SJM, Santiago, Chile. Contacto: pablo.roessler@sjmchile.org 
phenomenon. Through qualitative research techniques, applied between 2016 and 2017 in six schools in the municipalities of Santiago and Quinta Normal, it was possible to identify a set of discourses employed by Chilean adolescents about their national identity, which are exclusionary and hold the -immigrant "other" in low esteem. These discourses highlight a nationalist-territorialized mode of thinking, which upon constructing notions about subjects of legitimate rights, do not recognize their immigrant peers, who are perceived by native Chileans as bearers of everyday borders that place them in a de-territorialized and indebted position.

Keyconcepts: everyday borders, de-territorialization, national identities, nationalistterritorialized thinking, subjects of rights.

\section{Introducción}

Hoy el mundo vive una creciente interconectividad debida a los diferentes tipos de flujos transnacionales, sin embargo las naciones aún presentan un gran sentido de pertenencia en la gente (Castles, 2010; Chernilo, 2006). Esto se evidencia en los discursos e ideologías nacionalistas y securitistas que prevalecen en la elaboración de políticas migratorias en países receptores de inmigrantes internacionales (Faist, 2004), los que calan en el imaginario social de los nacionales en relación con estos "extraños externos", y tienen consecuencias en la forma de verlos como agentes que rompen la armonía aproblemática entre la persona y su nación (Wimmer \& Glick Schiller, 2002). En ese sentido, los inmigrantes quedarían fuera del goce legitimado de derechos y servicios del país al que llegan, de forma igualitaria con los nativos (Bravo, 2011; Thayer, Córdova y Ávalos, 2013). Todo lo anterior explica una percepción dominante, a nivel mundial, de la migración como un problema (Castles, 2010) desde la cual se ve al inmigrante con óptica de seguridad nacional y no de derechos. Se entiende así que, aún en un mundo con creciente interconectividad global, existen pensamientos nacionalistas que se relacionan con la construcción de sujetos legítimos de derechos, tanto a nivel de políticas, como de imaginario social.

De esta forma, en el marco de la globalización se da una división inequitativa de las riquezas a nivel mundial, por lo que surgen estrategias — como es el caso de las migraciones internacionales_- para sortear las desventajas que se producen en territorios menos favorecidos. Se da así respuesta a las vulneraciones vividas en territorios de origen, con el 
52 PENSAMIENTO NACIONALISTA-TERRITORIALIZADO Y PERCEPCIÓN DE "DESUBICAMIENTO" DEL INMIGRANTE: EL CAMINO HOSTIL DE LAS CONSTRUCCIONES DE IDENTIDADES CHILENAS EN LA CONVIVENCIA ESCOLAR - P. Roessler

fin de encontrar mejores oportunidades de vida (Canales y Zlolniski, 2001). Pero a pesar de que al migrar se imagina una mejor vida, a nivel mundial los migrantes tienden a concentrarse en sectores urbanos devaluados, donde el alojamiento solo es asequible debido a las malas condiciones de habitabilidad (Alguacil, 2006; Vigh, 2009), asociadas con su falta de medios económicos (Azócar, 2016), lo que los lleva a habitar viviendas de bajo costo, precarias y hacinadas (Stefoni, 2011; Tijoux, 2013). En países segmentados de Latinoamérica, como es el caso de Chile, los inmigrantes acceden — de forma parcial muchas veces, sobre todo cuando están en situación migratoria irregular- a servicios públicos, como salud (Cabiedes et al., 2017) y educación (Joiko y Vásquez, 2016; Stefoni, Stang y Riedemann, 2016) que, luego de las reformas liberales, han quedado paulatinamente mermados en relación con los privados (Dattwyler, Peterson y Rivas, 2017; Kaztman, 2001). Por dichas razones, su inserción se da generalmente en sectores sociales en los cuales los nacionales también se encuentran en situaciones de vulneración y exclusión social. De este modo, se deben tener en cuenta tanto las desventajas sociales que experimentan los migrantes (en territorio de origen y de acogida), como las de quienes pertenecen a los países receptores (Fundación Superación de la Pobreza, Fusupo, 2017), con los cuales los migrantes tienen un contacto más cotidiano en barrios, escuelas, trabajo y servicios públicos mermados. Al respecto, en muchos estudios se ha reportado una peor actitud hacia los inmigrantes en contextos donde los nativos perciben inseguridad social (Van Assche, Roets, Dhont \& Van Hiel, 2014), y donde han vivido experiencias de mucha competencia por los recursos escasos, en sociedades con altos niveles de inequidad social (Perry, Sibley \& Duckitt, 2013). Esto puede explicar el por qué en un país altamente desigual como Chile grupos de nivel socioeconómico bajo reportan peor actitud hacia la actual inmigración de origen latinoamericano (Sirlopú, Melipillán, Sánchez y Valdés, 2015).

Entonces, para hablar de identidades nacionales y migraciones en el presente artículo, se tematizará la exclusión y vulnerabilidad que viven muchos migrantes, como también muchos nacionales de los sectores sociales donde generalmente se insertan. Por ello, se considera desde dónde se habla de estos temas, para no caer en la omisión del contexto. 
De esta forma, la presente investigación, centrada en el espacio escolar, buscó comprender cómo expresan su identidad nacional los adolescentes chilenos que conviven con pares inmigrantes en sus aulas, con el fin de entender las manifestaciones de estas identidades en la convivencia escolar. Para tener mayores luces de ello, se describe cómo se ha concebido la construcción de identidades nacionales en la literatura, con sus dinamismos y rigidices, y su interacción con los fenómenos migratorios. Luego, se problematiza en torno a cómo se ha dado dicha interacción en Chile desde el forjamiento del proyecto Estado-Nación hasta hoy, considerando el contexto de inequidad social imperante.

\section{Estudios en torno a las construcciones de identidades nacionales cotidianas}

La identidad nacional se entenderá como un producto cultural de identificación social que debe estudiarse no solo desde su origen y diseño, sino también desde cómo ha ido cambiando su significado, para así comprender la legitimidad adquirida hasta hoy (Anderson, 1991).

Muchas veces se ha entendido la identidad nacional como una ideología hegemónica transmitida por las élites y el Estado, a través de dispositivos institucionales como la escuela, con el objetivo de conjugar a las personas dentro de un proyecto de pertenencia cultural llamado nación, que debe coincidir con los límites del territorio del Estado (Connor, 1978; Fox \& Miller-Idriss, 2008).

Otros estudios han realizado, sin dejar de lado la influencia institucional oficial, un giro agencial al considerar la respuesta cotidiana de los individuos, en las formas en que entienden, (re) producen, negocian y resisten diferentes aspectos de la identidad nacional diseñada por los grupos dominantes y divulgada por el Estado (Fox \& Miller-Idriss, 2008; Skey, 2009). En dicha línea, la configuración de identidades nacionales no es un hecho consumado ni asumido homogéneamente por todos los habitantes de un territorio nacional determinado, pues es también un logro contingente de la gente común en el cotidiano. Por un lado, la nacionalidad define el 
54 PENSAMIENTO NACIONALISTA-TERRITORIALIZADO Y PERCEPCIÓN DE "DESUBICAMIENTO" DEL INMIGRANTE: EL CAMINO HOSTIL DE LAS CONSTRUCCIONES DE IDENTIDADES CHILENAS EN LA CONVIVENCIA ESCOLAR - P. Roessler

discurso y prácticas de los habitantes, pero por otro, los individuos en cuanto actores, también definen nacionalidad desde su habla y prácticas cotidianas, dándose una performatividad en la construcción de lo nacional (Fox \& Miller-Idriss, 2008). En Chile, como se verá a lo largo del artículo, la identificación de lo chileno con lo racial (Riedemann y Stefoni, 2015; Tijoux, 2014), la geografía (Larraín, 2010; Thayer et al., 2013) y el lenguaje (Ayala, 2011) son expresiones de cómo se habla y actúa una identidad nacional, es decir, de cómo se (re)produce en el cotidiano. En dicho sentido, cabe señalar que en los adolescentes (grupo etario donde se centra este estudio) la manera de aprender la identidad nacional no es única, pues depende del contexto sociohistórico (Oppenheimer \& Barrett, 2011).

Entonces, se entenderá la identidad nacional como proyecto del Estado y las élites, pero que, junto con ello, es un invento dinámico que es constantemente actuado por las diferentes personas que transversalmente componen una nación en el tiempo (de su creación hasta hoy) y el espacio (en todo el territorio nacional). Por ello la nacionalidad debe investigarse también desde abajo (Hobsbawm, 1990).La globalización, por su parte, también imprime dinamismo a las identidades nacionales, pues el aumento de interconectividad global ofrece nuevos significados y maneras de imaginar el mundo (Appadurai, 2001). Por ejemplo, con las migraciones, los grupos étnicos tienen la posibilidad de reconstruir sus historias y proyectos sin la necesidad de circunscribirse a límites espaciales determinados, lo cual abre la posibilidad de desterritorializar las mismas identidades nacionales (Anderson, 1992). Así, se observa cómo en una era global lejos de dejar su relevancia, las identidades nacionales adquieren nuevos elementos de dinamismo (Chernilo, 2006).

Ahora bien, sería igualmente erróneo ignorar y naturalizar el marco nacionalista aún imperante en plena globalización, donde el mundo sigue siendo imaginado por naciones discretas (Wimmer $\&$ Glick Schiller, 2002). En efecto, se puede describir que en el transcurso del siglo XX crecieron los sentimientos de nacionalismo, influenciados por las Guerras Mundiales y Fría, lo cual ha traído consecuencias en la forma de ver a los inmigrantes: 
- Por un lado, son vistos como portadores cotidianos de la frontera, encarnándola cotidianamente a ojos de los nacionales, con características que los denotan como entes externos desterritorializados (Ramírez y Álvarez, 2009; Vigh, 2009).

- Son observados como agentes que rompen ciertas mimetizaciones entre la persona y su comunidad nacional de pertenencia, por ejemplo, se ve al inmigrante como outsider de las leyes compartidas ante el Estado y, por ende, como externo a los derechos garantizados (Bauböck, 2006; Wimmer \& Glick Schiller, 2002).

- Finalmente, emerge también una percepción estigmatizadora entre los nativos relacionada con que los inmigrantes absorberían del sistema sin contribuir (Olwig \& Paerregaars, 2011) lo cual, desde un punto de vista Maussiano, los deja en una situación de deudores permanentes.

Entonces se evidencia, en plena era de globalización, una tensión entre el dinamismo constante y desterritorialización en las identidades nacionales y, por otro, la (re)producción de identidades más bien clausuradas al territorio patrio, donde se nace o se tiene "sangre común".

\section{Identidades chilenas y procesos de migración en Chile}

En territorio chileno las identidades nacionales no han sido construidas inconexamente de los fenómenos migratorios, de este modo se han conformado por medio de reconocer (con valores positivos o negativos) a un otro (Thayer et al., 2013), es decir, no han sido algo estático, sino que se han ido configurando históricamente como proyectos de las élites y el Estado, con el afán de forjar soberanía en el territorio, pero también como logro de una gran diversidad de personas en el cotidiano. En esta línea "las identidades nacionales, y por lo tanto la identidad chilena, no son inmutables, se construyen en el tiempo y van cambiando" (Larraín, 2010, p. 6).

Primeramente, cabe señalar que se ha (re)producido un sí mismo blanco como base étnica de la identidad chilena, en exclusión 
56 PENSAMIENTO NACIONALISTA-TERRITORIALIZADO Y PERCEPCIÓN DE "DESUBICAMIENTO" DEL INMIGRANTE: EL CAMINO HOSTIL DE LAS CONSTRUCCIONES DE IDENTIDADES CHILENAS EN LA CONVIVENCIA ESCOLAR - P. Roessler

de lo negro e indígena, producto del legado colonial y de los proyectos de Estado-Nación en Chile (Riedemann y Stefoni, 2015; Tijoux, 2014). Entre los proyectos de conformación nacional del siglo XIX se encontró el proceso de migración selectiva de colonos europeos por parte del Estado, cuyo objetivo fue la búsqueda de un "progreso a la europea" para modernizar el país que se estaba formando, como también la higienización de la raza, asociada a una voluntad política arraigada en valores raciales que requieren a otro que sea la alteridad negada frente a lo blanco. Todos estos aspectos heredables no serían ajenos a las formas en que los chilenos observan hoy a sus países vecinos, generándose sentimientos de una condición racial ${ }^{3}$ específica del chileno, donde la sangre indígena, si bien hizo posible el presente mixto, se ha ido diluyendo hacia rasgos más asociados a lo blanco y europeo (Thayer et al., 2013).

Posteriormente, los triunfos en las guerras frente a Perú y Bolivia hicieron surgir percepciones de una superioridad ya no solo desde una visión racial, sino también desde lo militar e institucional (Larraín, 2010).

Ya en el siglo XX surge otra ola migratoria, en este caso con flujo contrario, donde muchos chilenos emigraron a otras latitudes producto del exilio y la represión política de la dictadura en los setenta, y al elevado desempleo en los ochenta. En este período, se dictó primero la Ley de Extranjería N¹094 (1975) y luego el Decreto Supremo N597 (1984), con componentes de fuerte orientación política para proteger las fronteras de un otro terrorista (Cano y Soffia, 2009). Dichas normas de extranjería rigen hasta hoy con ciertas modificaciones y continúan centradas en discursos securitistas, propios de la doctrina de seguridad nacional, con un escaso enfoque de derechos humanos, abriéndose el debate en torno a las consecuencias que generan aquellas normativas a nivel de la sociedad civil y en las maneras de observar a los actuales inmigrantes.

3 Si bien la noción de raza como elemento que antecede a la interacción social ha sido criticada desde las ciencias sociales, el sentido común la sigue utilizando como signo de distinción de grupos humanos (Thayer, 2013). 
Ya en la transición a la democracia (años noventa), se incrementó la estabilidad institucional, lo cual hizo de Chile un país atractivo a la inmigración (Cano y Soffia, 2009). Esta ola migratoria dista de la primera por sus condiciones, orígenes y rol del Estado (Tijoux, 2013). En un comienzo fue principalmente de origen peruano, pero considerando los datos del Censo 2017, en los últimos años ha aumentado en cantidad y diversidad, dentro de un marco mayoritariamente latinoamericano, lo cual se ha visto reflejado en el espacio escolar (Ministerio de Educación, Centro de Estudios, 2018).

Dicho aumento no ha traído aparejadas disposiciones de reconocimiento de parte del Estado, ni de la población chilena en general (Thayer et al., 2013). Desde el sentido común de los nativos, han mediado concepciones ideológicas nacionalistas en la disposición a convivir con los actuales inmigrantes en un mismo espacio territorial. Se han analizado entre ellas las nombradas distinciones raciales, como también algunas relacionadas con el uso del lenguaje, donde la variedad de español en Chile constituye una forma de distinción nacional (Ayala, 2011), que también actuaría de barrera en la convivencia con los inmigrantes (Pozo, 2014). Por otra parte, dichas distinciones en relación con un actual otro-migrante están también asociadas a elementos de carácter geográfico-normativos: los nativos tienen una percepción de pertenencia a un espacio institucional y geográfico particular llamado Chile que, resguardado por la cordillera de Los Andes, forma un aislamiento que posibilita la impermeabilidad de males raciales e institucionales predominantes en la región, dándose una geoidentidad (Thayer et al., 2013). Se vislumbra que las instituciones funcionan mejor que en el resto de la región, donde los chilenos se sentirían más cercanos al primer mundo que a sus vecinos (Larraín, 2010).

En síntesis, la aparición de los actuales inmigrantes — que se ven diferentes, hablan diferente y tienen una historia de pertenencia a otras geografías y leyes- hace emerger en el espacio público la presencia de personas que acceden parcialmente a las esferas de derecho lo cual, por su condición de externos, es legitimado (de mayor o menor modo) por la población receptora. Ese espacio que ocupan los inmigrantes expone una normalización de la discriminación (Thayer et al., 2013) la cual, dada su naturaleza no 
cuestionada, puede tener expresiones sutiles difíciles de detectar y, por ende, de combatir (Riedemann y Stefoni, 2015). Esto genera mermas en el ideal democrático, y requiere desde el Estado chileno avanzar hacia nuevas políticas centradas en lo humano, y desde la sociedad civil, en el plano de imaginarios y prácticas sociales (Thayer et al., 2013). El ámbito educativo es un ejemplo de ausencia de lineamientos claros para apoyar a las comunidades educativas en el proceso de inserción y reconocimiento de los estudiantes migrantes, dándole una sobrecarga a las instituciones escolares y a los docentes, a quienes se les hace difícil generar contenidos educativos flexibles y más integrales — fuera del currículo educativo nacional— que respondan a las particularidades del estudiantado y que busquen, por ejemplo, la protección igualitaria de derechos independientemente del origen (Jiménez, Aguilera, Valdés y Hernández, 2017; Servicio Jesuita a Migrantes, SJM, 2018; Stefoni et al., 2016).

Entonces, la merma en el reconocimiento a nivel institucional y social, dentro y fuera de la escuela, aporta a la existencia de sentimientos nacionalistas basados en un pensamiento territorializado por límites nacionales en el reconocimiento y construcción de quiénes son los sujetos portadores de derechos (Hale, 2005).

Finalmente, hay que tener en cuenta el marco de segmentación social que hoy prevalece en varias ciudades latinoamericanas y chilenas, y cómo esto trae experiencias de aislamiento y exclusión de las corrientes principales presentes en la sociedad (Dattwyler et al., 2017), con las que se socializan los menores de sectores vulnerables. Esto traería al menos dos secuelas:

- Dicho aislamiento afecta el acceso a las estructuras de oportunidades que ofrece una sociedad (acceso a bienes, servicios y desempeño de actividades), dejando a los pobres urbanos a la deriva de una mayor competencia por recursos y servicios más escasos.

- Las configuraciones de sentimientos de ciudadanía o de horizonte social común no son ajenas a las experiencias de exclusión (la no voz) desde las cuales se van socializando los menores de sectores vulnerables, forjándose un sentimiento de una falsa integración social (Kaztman, 2001; Perry et al., 2013). 
Lo anterior podría tener consecuencias en las formas en que los nativos van construyendo sus identidades chilenas de un modo clausurado en relación con un otro-inmigrante, por la competencia de oportunidades escasas (Fusupo, 2017) y/o porque ni ellos mismos se sienten realmente integrados.

\section{Método}

La metodología del estudio fue de carácter cualitativa. Para recolectar la información se realizaron grupos focales (6) y entrevistas individuales (18) con adolescentes chilenos. Estos instrumentos se aplicaron en 2016 en seis establecimientos educacionales de las comunas de Santiago y Quinta Normal, de los cuales tres tienen un mayor porcentaje de matrícula migrante (sobre el 14\% de su matrícula total), y los otros tres tienen un porcentaje menor, pero incipiente de escolares extranjeros.

El estudio se centró en adolescentes, dada la importancia de esta etapa del curso de vida en la construcción de una identidad propia y de su entorno (Reyes, 2009). Por su parte, se centralizó en establecimientos municipales dado que es el tipo de dependencia escolar donde se han insertado mayormente los estudiantes migrantes (Tijoux, 2013). Según datos del Sistema Información General de Estudiantes, del Ministerio de Educación, SIGE (2016) un 55\% de los 61.086 estudiantes extranjeros registrados se concentraba en este tipo de dependencia escolar, por lo cual serían los espacios donde se daría mayor contacto cotidiano entre nativos chilenos y pares foráneos. Por último, cabe recalcar que los establecimientos municipales concentran a la población (nacional y migrante) más desfavorecida del país. Las seis escuelas de dependencia municipal en las cuales se realizó el trabajo de campo, según datos de la Junta Nacional de Auxilio Escolar y Becas, Junaeb (2016), poseían un índice de vulnerabilidad (IVE-SINAE) que fluctúa entre un 59\% en una de ellas, y un $87 \%$ en dos de estas.

Ahora bien, partiendo por los instrumentos para recabar datos, primeramente se utilizó un cuestionario autoaplicado a todos los adolescentes de séptimo, octavo año básico y primer año medio 
60 PENSAMIENTO NACIONALISTA-TERRITORIALIZADO Y PERCEPCIÓN DE "DESUBICAMIENTO" DEL INMIGRANTE: EL CAMINO HOSTIL DE LAS CONSTRUCCIONES DE IDENTIDADES CHILENAS EN LA CONVIVENCIA ESCOLAR - P. Roessler

de los seis establecimientos (585 respondieron efectivamente), donde se preguntaba con quiénes del curso presentaban contactos más profundos, ya sea de cooperación, amistad o voluntarios, y con quiénes no ${ }^{4}$. Con esto se detectó, por medio de análisis de sociograma con el software de análisis de redes UCINET6, la ausencia y presencia de contacto voluntario entre nativos e inmigrantes. Se buscó así seleccionar a los adolescentes chilenos para los grupos focales y entrevistas individuales semiestructuradas, siguiendo la intencionalidad de que participaran estudiantes nativos con mayor y menor profundidad de contacto con sus pares inmigrantes. Todo esto para luego indagar formas específicas de discursos sobre identidades chilenas en los resultados cualitativos, teniendo en cuenta distintos ambientes de contacto entre chilenos e inmigrantes, en cuanto a cantidad (proporción de matrícula migrante en el establecimiento) y calidad (presencia o no de vínculos voluntarios con pares inmigrantes).

Las preguntas de los grupos focales se realizaron desde una operacionalización derivada de los objetivos de investigación. En dicha línea, se buscó comprender elementos de las identidades chilenas de los que expresan sentirse portadores en sus narrativas (Fox \& MillerIdriss, 2008). Acá se exploró qué entienden por nación, y qué significa para ellos. Las entrevistas semiestructuradas, por su parte, buscaron profundizar en los temas emergentes en los grupos focales a través de diferentes metodologías acordes con la edad de los participantes.

Luego la información recabada se analizó entre 2016 y 2017 con el software de análisis cualitativo de datos asistido por computadora NVIVO, basándose en lineamientos de la teoría fundamentada, al tener esta un enfoque de análisis de datos cualitativo de tipo emergente, donde los códigos surgen de la lectura de los datos más que emanar desde un marco anterior más cerrado (Charmaz, 2006). En dicho sentido el análisis presentó un carácter inductivo de investigación: se buscó cuidadosamente que las categorías surgieran de las narraciones de los participantes.

4 No se preguntaba por nacionalidad de origen, solo por nombre y apellido de compañeros. El origen nacional se detectaba posteriormente con información de cada escuela. 
De igual manera, vale recalcar que tanto la aplicación de los instrumentos como el análisis de la información emergente se realizaron desde un paradigma interpretativo, esto es, sin dejar de lado cómo se forma el conocimiento entre quien investiga y quien es investigado, por lo cual es imposible dejar de lado las diferentes biografías ahí involucradas, las cuales se inscriben en un contexto (Mieles, Tonon y Alvarado, 2012; Roulston, deMarrais \& Lewis, 2003). Por esta razón la intersubjetividad fue el medio para conocer la realidad social a investigar.

\section{Resultados}

En el trabajo de campo, se halló un conjunto de discursos de los adolescentes en torno a la identidad chilena que se forjan más bien cerrados, excluyentes y de baja valoración hacia un otro-inmigrante. En estas expresiones se daba valoración negativa a la distinción entre un yo-chileno y un otro-inmigrante, relevándose un pensamiento nacionalista-territorializado de parte de los adolescentes chilenos al momento de construir sujetos legítimos de derecho en sus discursos, donde sus pares inmigrantes no cabrían. Lo anterior, deviene de elementos de distinción nacional que (re)producen los adolescentes nacionales en sus imaginarios cotidianos, en relación con sus pares inmigrantes, posicionándolos como portadores cotidianos de fronteras, las cuales deben ir cruzando diariamente y no solo al haber ingresado al país (Ramírez y Álvarez, 2009; Vigh, 2009). En consecuencia, dichas fronteras dejan al inmigrante en una posición visible y continua de desterritorializado.

Se describirá brevemente el marco de inequidades sociales desde donde los adolescentes chilenos participantes expresan sus identidades nacionales, los cuales se sienten chilenos, pero pertenecientes a un sector social poco privilegiado. Luego, se explicará cómo dichos adolescentes van (re)construyendo cotidianamente su distinción nacional en relación con un otro-inmigrante, por medio de fronteras de tipo lingüísticas, raciales, legales y territoriales. Finalmente, se presentará cómo se categoriza al inmigrante que queda fuera de dichas fronteras como desterritorializado y, por ende, como externo a considerarse como sujeto legítimo de derecho. 
62 PENSAMIENTO NACIONALISTA-TERRITORIALIZADO Y PERCEPCIÓN DE "DESUBICAMIENTO" DEL INMIGRANTE: EL CAMINO HOSTIL DE LAS CONSTRUCCIONES DE IDENTIDADES CHILENAS EN LA CONVIVENCIA ESCOLAR - P. Roessler

\section{Desde dónde expresan su identidad nacional}

Los adolescentes participantes señalaron que si bien los chilenos tienen muchas características comunes, y que ellos mismos se sienten orgullosos en cuanto chilenos, habrían también ciertas rupturas entre las cuales ellos se sitúan, existiendo una de criterio económico:

[los sectores privilegiados] siempre hacen cosas que nos perjudican a nosotros ... En que los cuicos ${ }^{5}$ por tener más plata se creen mayor que uno ... Ellos son los verdaderos ignorantes, los que en realidad roban y cosas así. Uno debería ganar harta plata y gracias a ellos unos ganan 250 , y eso es muy poco pa' las cosas que cuestan [E_Hombre 1, Santiago].

Los cuicos casi todos tienen nanas... les hacen sus camas, en cambio en las poblaciones no hay como eso po', también los cuicos andan en los medios autos, en las medias camionetas, se visten con ropa cara [FG_Hombre, Santiago].

Así, se posicionan como parte de sectores menos privilegiados, en los cuales se experimenta el aislamiento y exclusión de las corrientes principales. Ser parte de dicho sector socioeconómico impacta en su acceso a oportunidades, debiendo competir por derechos y/o beneficios, y también impacta en las configuraciones de sus sentimientos de ciudadanía. De esta manera se hace más difícil reconocer en otros, en este caso sus pares inmigrantes, sujetos de derecho, dándose incluso la sensación de que poseen un mejor trato que los mismos chilenos.

Pero ellos, generalmente suelen ser muy ... tomados en cuenta. Más que los propios chilenos ... encuentro que por eso me molestan un poco los extranjeros, porque siento que ellos tienen muchos más beneficios que nosotros. Más que los chilenos [ $\mathrm{E}_{-}$ Mujer5, Santiago].

Vivir en contextos vulnerables y de exclusión permanente de las oportunidades que ofrece la sociedad, el Estado y el mercado

5 Individuos de sector socioeconómico alto. 
puede asociarse con mirar el mundo de una manera competitiva lo cual puede producir actitudes menos favorables hacia los inmigrantes (Fusupo, 2017; Kaztman, 2001). Se tendrán en cuenta estos contextos de inequidad y exclusión en los que se han socializado los adolescentes chilenos participantes del estudio al momento de analizar cómo expresan identidades chilenas más clausuradas y excluyentes en relación a un otro-inmigrante, posición en la que se encuentran sus pares de aula foráneos.

\section{Fronteras de distinción nacional}

En los discursos de los adolescentes se observan elementos asociados a lo chileno y que emergen como fronteras en la distinción yo-chileno y otro-inmigrante. En ese sentido, emergieron fronteras de distinción que se asocian a: un uso particular del español, una condición de aspectos físicos o raciales también particular, y el nacer, tener ascendencia y crecer en el territorio chileno.

La primera frontera habla de una identificación de ellos mismos como chilenos asociada con un uso particular del lenguaje español en Chile. Esto fue el elemento de identidad con lo chileno más reiterado tanto en los grupos focales como en las entrevistas individuales. En sus narrativas los participantes caracterizaban recurrentemente a los chilenos en general, y a ellos mismos en particular, en cuanto a la forma de hablar. Se identificaban — como ellos nombraban — con un lenguaje español-chileno, esto es, con un uso particular de la lengua española reflejada en un dialecto/variedad que llega a tornarse, según ellos, en un idioma propio.

dicen que hablamos español-chileno, que tenemos palabras creadas que nadie entiende, frases muy raras. Así que me siento muy chilena con eso, me llega a dar demasiada risa, porque es español-chileno ... las frases creadas por Chile. Le he preguntado a una compañera, que yo soy muy chilena pa' hablar y como que le digo las cosas, y como que no me entiende. Ella es colombiana y no me entiende. Me dice qué es eso, y no me entiende. A cada momento le digo como esto significa esto, como perro muerto, o estai peinando la muñeca, o ya po', vamos al tiro... eso es lo que me hace más chilena [E_Mujer3, Santiago]. 
64 PENSAMIENTO NACIONALISTA-TERRITORIALIZADO Y PERCEPCIÓN DE "DESUBICAMIENTO" DEL INMIGRANTE: EL CAMINO HOSTIL DE LAS CONSTRUCCIONES DE IDENTIDADES CHILENAS EN LA CONVIVENCIA ESCOLAR - P. Roessler

Es que nuestro vocabulario es como... Es de español, pero se le llama "chilensis", por eso es que nos encuentran muy ordinarios, pero es como nos hemos criado todos, por eso se le llama 'chilensis', los de otro país no entiende nuestro vocabulario [FG_ Hombre, Quinta Normal].

Los adolescentes entrevistados caracterizaron este lenguaje español-chileno como un español mal hablado o alterado, relacionado con un uso normalizado del garabato, como también de modismos. De igual manera señalaron sentirse identificados con dicha variedad del español. En ambientes escolares de mayor contacto con inmigrantes, indicaron haberse concientizado más profundamente del español-chileno al comunicarse con pares extranjeros también hispanohablantes. Dicho uso del español en el contacto comunicativo verbal con pares inmigrantes producía una sensación identitaria de que "solo entre chilenos se entienden", señalando dificultad de comunicación verbal no solo con pares de origen haitiano (cuya lengua materna es el creole), sino con pares inmigrantes también hispanohablantes.

Yo tengo compañeros chilenos, y todos también hablan con garabatos, como eso los hace identificarse a los chilenos [FG_ Hombre, Santiago].

A veces uno habla con personas de otros países con su propio idioma de uno y no te entienden [FG_Mujer, Santiago].

Porque, cuando hay una persona hablando, a los colombianos que están en el curso hablando, no se les entiende ... Es que de primera cuando llegan, hablan muy rápido y no se les entiende mucho, pero después empiezan a hablar más lento y se acostumbran [E_ Hombre4, Santiago].

De este modo, los adolescentes participantes identifican en el lenguaje un elemento de distinción nacional. Exponen que el particular español-chileno los identifica y diferencia de sus pares inmigrantes, llegando en ocasiones a producir dificultades en la comunicación y relacionamiento mismo. Entonces, se ve que el lenguaje funciona como vehículo para representar una identidad 
social, en este caso nacional (Ayala, 2011), con el cual los adolescentes van imaginando/generando fronteras entre un yo-chileno y un otroinmigrante (Pozo, 2014), al significar una variedad de español como propia de una comunidad encasillada en un territorio-nación.

Siguiendo con las fronteras de distinción de lo chileno, se llega a las relacionadas con los rasgos físicos. Al respecto, predominó en las entrevistas una percepción de una condición racial específica del chileno (Thayer et al., 2013), dada por rasgos físicos que diferenciarían a los nativos en general con los nuevos inmigrantes de origen latinoamericano (Riedemann y Stefoni, 2015; Tijoux, 2014).

Surge como frontera o significante distintivo de la identidad chilena una tonalidad de piel, que no se identifica ni con lo muy blanco, ni con lo muy negro. De igual forma, esta frontera de tipo racial se construye en relación con un otro significante visible, un otro más negro o más indígena que es inferiorizado, y que trae consigo significados negativos arraigados, a diferencia de lo que pasa con el otro más blanco, asociado con el barrio alto e imágenes de los medios de comunicación y la globalización. Muchos de sus compañeros inmigrantes se situarían en el sector del otro más negro.

Recurrentemente en el discurso, los adolescentes posicionaron al más negro como víctima de discriminación racista, llegando a declararse testigos de expresiones de violencia por parte de otros chilenos en la calle, o en la misma escuela por parte de otros compañeros. Si bien señalan que la discriminación racista directa si existe en Chile, prácticamente nunca sería ejecutada por ellos mismos, sino que siempre es otro chileno el que la ejerce: "el chileno de por sí, es racista". Solo vendría de ellos mismos lo considerado como bromas, pero que están alimentadas con categorías racistas.

Por ejemplo, no sé, como que los discriminan cuando jugamos a la pelota. Dicen como que él porque es de otro color pa' allá... ahí siempre veo que les dicen que te vayai de mi casa así, como cosas así, como peleas. Les dicen como que tu eris negro, no eris de aquí. Y en el colegio igual se han visto cosas así [E_Hombre7, Quinta Normal]. 
La mayoría molestan, por el color de la piel, todo eso ... un compañero extranjero, con una chilena, empezaron a pelear, lo molestaron por el tema del color, él se enojó y la tiró al suelo [E_Hombre2, Santiago].

Unos pequeños chistes racistas que se me escapan.

E: ¿Cómo son esos chistes?

Ehh... son chistes típicos medio racistas que pueden insultar a todos los países menos a Chile (...) ¿Cómo meter a quince niños de Somalia en un frasquito?

E: ¡Qué difícil! ¿Cómo?

Tirándoles una miga pan [E_Hombre9, Quinta Normal].

Sale a flote una normalización de la discriminación como condición impresa del chileno, la cual deriva desde la condición racial específica que se habría ido formando históricamente como característica identitaria del chileno (Thayer et al., 2013). Lo blanco constituye así una referencia nacional, en exclusión de lo más negro o indígena, lo que se expresa en los discursos adolescentes en el uso de categorías raciales que contendrían un significado peyorativo y de inferioridad (Riedemann y Stefoni, 2015; Stefoni et al., 2016; Tijoux, 2014). Van actuando así lo chileno en su vida cotidiana, también por medio de categorías raciales, dándose en este sentido una performatividad en la manera de decir y hacer la nación (Skey, 2009; Fox \& Mill-Idriss, 2008).

Por último, una tercera frontera de distinción de lo chileno en relación a un otro-inmigrante registrada en sus discursos es una identificación con el territorio chileno en sí, en cuanto espacio donde se nace, se tiene ascendencia, y el cual posee una geografía particular con la cual se convive.

Se identifican como chilenos por haber nacido dentro de las fronteras territoriales de la nación chilena e incluso llegan a decir que son chilenos de sangre o genes, instalando un componente biológico a la pertenencia nacional. 
Es un orgullo ser chileno, porque naciste acá y vai a morir acá ... Porque donde nació una persona tiene que estar orgulloso porque nació ahí y se va a morir ahí [E_Hombre4, Santiago].

¿Qué me hace sentir chileno? Que, en mi casa, aunque todos somos chilenos de nacimiento, de genes y todo ... Bueno. Aparte de tener algo que directamente diga desde tal parte de mi familia hasta esta parte son chilenos [E_Hombre9, Quinta Normal].

Igualmente se verifican identificaciones con el territorio geográfico en sí, lo que se asocia a una construcción de una singularidad territorial imaginada del espacio en Chile (Larraín, 2010; Thayer et al., 2013), que tendría paisajes particulares y elementos de límite con países vecinos, como la cordillera de Los Andes y la presencia de mar en todo el territorio.

Porque si dicen que si es de Chile, por el barco, porque todo Chile está pegado al mar casi. Sí, igual que la Cordillera, atrás se nota ... Porque está la Cordillera [E_Hombre8, Quinta Normal].

Yo el año pasado tenía un compañero que era boliviano y que siempre lo molestaban, como no tenía mar ... [FG_Hombre, Quinta Normal].

Eso se acercaría al concepto de geoidentidad llamado por Thayer et al. (2013), donde la cordillera y el mar tendrían la función de separar a Chile de los vecinos, configurando una forma singular de ser chileno. De este modo, se va aprendiendo y (re)haciendo lo chileno con criterios de espacio geográfico, mezclado con elementos normativos del territorio mismo, como el nacer en esta tierra, tener ascendencia familiar en ella y el haberse socializado en conjunto con las particularidades de Chile. Se van así también apropiando de lo chileno por criterios de índole (legal) territorial (Skey, 2009; Fox \& Mill-Idriss, 2008).

De esta forma, se evidencian fronteras que develan una forma de encasillar lengua, raza y territorio como particularidades de una sociedad nacional — la chilena_, que se refleja en las maneras cómo los adolescentes entrevistados aprenden, pero también van hablando 
y (re)haciendo lo que entienden por lo chileno y que, finalmente, los distingue de todo lo demás, donde se encuentran categorías a las que se les imprime muchas veces menoscabo, en las que sitúan a los actuales inmigrantes que conviven con ellos en el espacio escolar.

En la relación entre estudiantes nativos y compañeros inmigrantes, la reproducción de dichas tres fronteras que marcan la distinción de lo chileno se cristalizan, produciendo un posicionamiento de los inmigrantes como desterritorializados en Chile al quedar fuera de esas fronteras.

\section{Construcción territorializada de sujetos legítimos de derecho}

La cristalización del yo-chileno en Chile, que habla como chileno, se ve como chileno y que habita su territorio original (natural) y legal de pertenencia histórica, dialoga con un sentimiento nacionalistaterritorializado de los estudiantes entrevistados, donde contraponen las tres fronteras analizadas de distinción de lo chileno en una diferenciación ante los inmigrantes. Dichas fronteras diarias sitúan al inmigrante visiblemente como desterritorializado en Chile. Son fronteras que se les imprimen y denotan su posición, a ojos del chileno, en una ubicación territorial y legal que no sería la suya original (Bravo, 2011; Ramírez y Álvarez, 2009; Wimmer \& Glick Schiller, 2002).

Además de posicionar al inmigrante como desterritorializado, se le ve como un deudor original. Los adolescentes chilenos entrevistados presentarían una visión estigmatizadora de los inmigrantes que, desde un punto de vista Maussiano, absorberían sin contribuir (Olwig \& Paerregaars, 2011). Estarían así los nacionales, concibiendo la recepción como un regalo otorgado al inmigrante, y que los deja en una posición de deudores desde el origen, casi congénita ante los chilenos, quienes los aceptan en su territorio, su patria natal, pero siempre en una condición de visitante.

Entonces, dicho posicionamiento del inmigrante como desterritorializado y como deudor original que solo se beneficia y no contribuye, hace emerger hostilidades cotidianas entre los 
adolescentes chilenos y sus pares inmigrantes en espacios comunes de la escuela. Estas dinámicas ocurren cuando los inmigrantes (sobre todo en las escuelas donde había más presencia de extranjeros) muestran cierta seguridad en este espacio ajeno. Aparecería así, en el cotidiano del espacio escolar, una percepción de desubicamiento del inmigrante. Desubicado cuando opina de ciertos temas significados de mayor autoridad para el que se distingue como chileno, o desubicado al apropiarse con seguridad de ciertos espacios chilenos, sin adaptarse a su situación.

Así se da una metáfora del aceptarlos, incluso llegando a ser amigo, pero sin que pasen ciertos límites, sin quitarles jamás la etiqueta de visitantes y futuros semiciudadanos (Bauböck, 2006). Se detectaron dos expresiones de este tipo de percepción de desubicamiento del inmigrante en los discursos de los entrevistados: una que habla de regalos y críticas, y otra que remite a apropiaciones indebidas.

\section{Entre regalos y críticas}

La primera expresión remite a la relación entre regalos y críticas, es decir, la percepción de entrega de ciertos regalos específicos a los inmigrantes por parte de Chile y los chilenos. Según lo que señalan los adolescentes chilenos, los dones que se les entregan son: trabajo, dónde vivir, becas, salud, e incluso "se les da todo", pero el don más importante de todos, el regalo más preciado, es el aceptarlos en su país, es decir, la recepción. En dicho sentido, lo que les molesta a los chilenos entrevistados sería que, en discusiones cotidianas en la escuela, emerjan críticas desde los inmigrantes hacia "lo nuestro". Según lo que señalan los entrevistados estas críticas emitidas por los inmigrantes apuntan a:

- los chilenos y sus formas de ser, esto es, que digan que los chilenos son menos fiesteros que ellos, por ejemplo, al no existir carnavales en el territorio nacional; o que los chilenos son flaites $^{6}$, que roban, hablan mal o tienen malas costumbres;

6 "Individuos que encarnan el estereotipo del joven de estrato bajo normalmente vinculado al mundo delictual" (Rojas, 2012, p. 151). 
70 PENSAMIENTO NACIONALISTA-TERRITORIALIZADO Y PERCEPCIÓN DE "DESUBICAMIENTO" DEL INMIGRANTE: EL CAMINO HOSTIL DE LAS CONSTRUCCIONES DE IDENTIDADES CHILENAS EN LA CONVIVENCIA ESCOLAR - P. Roessler

- los servicios públicos, es decir, que la salud y educación son malas en Chile, elementos que — cabe recalcar-, los mismos adolescentes chilenos critican en sus discursos, pero que al parecer serían temas de legitimidad del chileno hablarlos;

- al país en general, por ejemplo, decir que Chile es un país más pobre de lo que creen los chilenos; que el trabajo es malo; que hay mucha contaminación; que Chile es feo; y que finalmente, es un mal país en su sentido genérico.

Ante estas críticas, ante el atrevimiento del inmigrante desterritorializado y deudor a emitirlas, surgen respuestas (y que serían justificadas para la mayoría de los adolescentes chilenos entrevistados), que van desde molestarse por la crítica, enojarse, no querer juntarse más con extranjeros, hasta incluso participar en peleas más violentas. Estas respuestas apuntarían a defender lo chileno.

Porque, por ejemplo, no soporto eso de que nos digan que somos como un mal país, que somos pobres, porque ellos vienen igual pa' nuestro país y les dan trabajo, les dan comida, les dan becas, les dan salud, les dan todo. Cosas que a veces ni los mismos chilenos a veces tenemos. Porque, por ejemplo, uno necesita operarse y se muere esperando un trasplante, o lo que sea [E_Mujer5, Santiago].

Claro, lo que molestaría sería también como lo ... como lo bulliciosos que son, porque los que vienen de países como de carnavales, y dicen que Chile es fome y cosas así, es como un poco más molestoso [FG_Mujer, Santiago].

... pero hay algo que no me gusta. Que vengan aquí a picar aquí 'ay, qué la educación, que no sé qué cosa', pero yo creo que si es una visita no tiene por qué criticar. Yo no estoy tampoco 'esta es la mejor educación', pero no tienen porqué venir aquí a imponer lo que tienen [E_Mujerl, Santiago].

... es que los chilenos defienden su país, eso es lo que hacen, por eso hay mucha pelea contra los peruanos [E_Mujer2, Santiago]. 


\section{Apropiación indebida}

La segunda expresión remite a una percepción de los adolescentes, emergente cuando el inmigrante olvida su condición de visita y comete apropiación indebida del espacio o de ciertas situaciones. Acá se dan dos síntomas:

- una actitud indebida a ojos de los nacionales sería cuando el inmigrante muestra seguridad con el espacio, que sería eternamente prestado, y se apropia de este; y

- otra actitud indebida también sería no adaptarse, con manifestaciones como seguir hablando igual o comportándose como lo harían en su casa (país de origen), o el tomar actitudes indebidas en el espacio público como "mirar feo" a un chileno, o "ponerse choros (desafiantes) y agrandados" con sus compañeros chilenos.

No me molesta que haya extranjeros, pero hay gente que es muy pesada, que vienen de otros países y creen como si fuera de él [FG_Mujer, Santiago].

A los extranjeros, porque llegan acá a Chile y se comportan como en su casa. Por ejemplo, llega acá un extranjero a Chile y se pone a comportar como se comportan allá, no cambian eso, como que no se adaptan ... En mis vecinos peruanos, dejan la basura al lado, todo eso, o sea salen con chalas, a pata pelada. O en los compañeros a veces, se comportan como se comportan allá, en la forma de hablar, en lo que hacen, hablan rápido, no se les entiende nada [E_Hombre2, Santiago].

Entonces por medio de la crítica a lo nuestro, o de la apropiación indebida, se da una especie de atrevimiento del inmigrante a ojos de los nativos, el que se relaciona con no estar pagando bien la deuda original que significa recibirlos en el país, y se asocia con dejar su condición menor propia de un deudor y de un visitante desterritorializado. Serían un grupo que, a ojos de los nativos, absorbe sin contribuir (Olwig \& Paerregaars, 2011). Así, se activa un sentimiento nacionalista-territorializado, desde discusiones diarias o actitudes que podría adoptar el inmigrante. 
72 PENSAMIENTO NACIONALISTA-TERRITORIALIZADO Y PERCEPCIÓN DE "DESUBICAMIENTO" DEL INMIGRANTE: EL CAMINO HOSTIL DE LAS CONSTRUCCIONES DE IDENTIDADES CHILENAS EN LA CONVIVENCIA ESCOLAR - P. Roessler

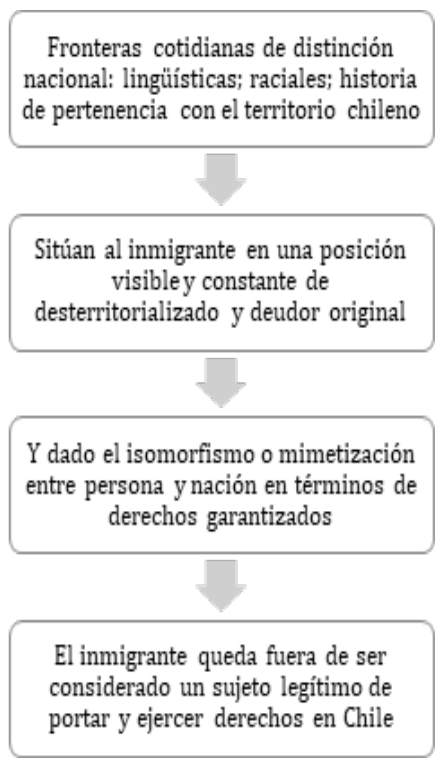

Figura 1. Expresiones de identidades chilenas más cerradas y excluyentes en relación con un otro migrante.

Fuente: Elaboración propia.

Es así que los inmigrantes deben ir cruzando fronteras cotidianamente, las que los posicionan visiblemente en un permanente carácter desterritorializado y de deudor original en Chile, a ojos de sus mismos compañeros de aula. Cabe considerar que se replica y (re)construye, a nivel de adolescentes, y en una etapa formativa (Reyes, 2009), una construcción nacionalista-territorializada de sujetos legítimos de derecho en Chile, considerando a los inmigrantes como portadores de ello, pero de sus Estados (Wimmer \& Glick Schiller, 2002). Siguiendo a Thayer et al. (2013) se produce un no reconocimiento de los adolescentes inmigrantes como verdaderos (futuros) ciudadanos en suelo chileno, y con ello se perciben como individuos que legítimamente deben ser excluidos y pobres en derechos. Sería una forma de discriminación normalizada, sutil, difícil de detectar y, por ende, de combatir (Riedemann y Stefoni, 2015; Tijoux, 2013), que apunta a su formación como sujeto de derechos.

Siguiendo a Wimmer y Glick Schiller (2002), en los imaginarios de los adolescentes entrevistados se daría una prevalencia 
de un isomorfismo o mimetización entre persona y nación, en temas de derechos garantizados ante el Estado, donde el inmigrante sería percibido como perturbador de dicha mimetización y como ajeno a las leyes y derechos compartidos ante el Estado chileno. Estas construcciones llegan a desembocar en expresiones de hostilidad al momento en que los adolescentes inmigrantes buscan hablar o apropiarse de ciertos temas y/o espacios que serían propios de los chilenos y no permitidos para ellos, dándose una merma en la convivencia escolar entre chilenos e inmigrantes, con expresiones que van desde discusiones y segmentación, hasta peleas más violentas.

Siguiendo a Fox y Mill-Idriss (2008) se verifica una forma en que los adolescentes entrevistados aprenden y (re)producen sus identidades chilenas, lo que expone un modo de performatividad de lo nacional que se da por medio de actos y discursos enmarcados en una distinción y clausura ante los actuales inmigrantes latinoamericanos que llegan a Chile, los cuales son observados como sujetos parciales o incompletos de derechos (Thayer et al., 2013). Esto muestra ciertas rigideces aún prevalentes al momento de construir identidades nacionales: en plena era de interconectividad global en la cual, a pesar de emerger nuevas opciones de forjar identidades desterritorializadas de un espacio delimitado (Appadurai, 2001) a los adolescentes chilenos entrevistados les complica esa condición que portan sus pares inmigrantes.

De igual modo no se puede desechar desde dónde expresan su identidad nacional, esto es, desde sectores excluidos en los cuales el acceso a estructuras de oportunidades y a derechos se verían mermados, quedando a la deriva frente a una mayor competencia por recursos, servicios y bienes escasos en cantidad y calidad (Dattwyler et al., 2017; Kaztman, 2001). En relación con ello se debe considerar una potencial peor actitud desde los nativos hacia los inmigrantes en contextos sociales donde se percibe inseguridad social y se mira el mundo desde la competitividad, debido a la exposición a ambientes de inequidad social donde se daría un mayor roce por los recursos escasos (Perry et al., 2013; Sirlopú et al., 2015; Van Assche et al., 2014). Emergería así un malestar por la percepción de que individuos externos que hablan diferente, se ven diferentes y/o que simplemente 
74 PENSAMIENTO NACIONALISTA-TERRITORIALIZADO Y PERCEPCIÓN DE "DESUBICAMIENTO" DEL INMIGRANTE: EL CAMINO HOSTIL DE LAS CONSTRUCCIONES DE IDENTIDADES CHILENAS EN LA CONVIVENCIA ESCOLAR - P. Roessler

no tienen una historia de pertenencia con el país - y que por ello se perciben como desterritorializados y deudores por haber sido recibidos - vengan a competir por beneficios (Fusupo, 2017) ya mermados y por oportunidades de surgir.

\section{Conclusiones}

Se halló un conjunto de discursos de los adolescentes acerca de la identidad chilena, los que se forjan más bien cerrados, excluyentes y de baja valoración hacia un otro-inmigrante. Esto tiene su raíz en la construcción cotidiana de fronteras de distinción nacional de parte de los adolescentes chilenos, las que serían de tipo lingüísticas, asociadas con el uso de la variedad de español-chileno; raciales, relativas a la percepción de una condición racial específica del chileno; y legalterritoriales, que remiten a una pertenencia con el espacio geográfico chileno, como territorio en el cual se nace, se tiene ascendencia y que tiene características particulares con las cuales los chilenos se socializan.

Las nombradas fronteras de distinción de lo chileno sitúan visiblemente al inmigrante que queda fuera de esos límites como desterritorializado, pues no habla como chileno, no se ve con rasgos chilenos y/o no tiene pertenencia con el espacio nacional. Además, perciben al inmigrante como deudor por haber sido recibido en el país. Esto emplaza a la reflexión de cuándo realmente el inmigrante cruza la frontera, si al ingresar al territorio chileno, o si la frontera sería una condición que porta consigo y que debe seguir cruzando permanentemente en el cotidiano (Ramírez y Álvarez, 2009; Vigh, 2009). Entonces, dada su condición desterritorializada y de deudor original, y teniendo en cuenta que en el imaginario social de los adolescentes chilenos participantes prevalece una forma nacionalistaterritorializada de construir sujetos legítimos de derechos, se entiende que el inmigrante en Chile (entre ellos sus pares inmigrantes) quedaría como un sujeto legítimamente excluido de ejercer derechos.

Yo igual he visto cómo los extranjeros llegan a Chile y empiezan a criticarlo, y eso igual está mal porque Chile, como dice el [xx], les da todo, porque es un buen país, entonces que un extranjero 
venga y lo critique cuando en verdad está viviendo aquí, y le están dando trabajo y esas cosas, no puede venir a criticarlo, entonces igual a veces los chilenos nos enojamos por eso, y somos un poco discriminadores también [FG_Hombre, Santiago].

Yo si estuviera en Perú, no criticaría, porque de algún modo es su país y me están aceptando [E_Mujer5, Santiago].

En este caso se ve cómo en discusiones cotidianas se replicaría, en edad escolar y adolescente, un bajo o nulo reconocimiento cívico igualitario al de los chilenos (Bravo, 2011; Thayer et al., 2013), que legitima actitudes discriminatorias vistas como normales (Riedemann y Stefoni, 2015; Tijoux, 2013), pero también como algo que se debe hacer.

Así emerge la percepción de desubicamiento del inmigrante al momento de buscar el ejercicio de derechos, tales como opinar sobre elementos considerados como chilenos, o al momento de apropiarse de espacios y situaciones, mostrando seguridad en una tierra ajena. Esto constituiría un atrevimiento del inmigrante, pues además de ser sujeto desterritorializado, no estaría pagando la deuda original que significa haber sido recibido en Chile.

Estas percepciones, impregnadas de categorías nacionales incuestionadas y dadas por hecho, pero que son (re)producidas en el cotidiano, traen implicancias a nivel de convivencia escolar, produciendo hostilidad entre adolescentes nacionales e inmigrantes, que irían desde discusiones y segmentación, hasta peleas violentas.

Dicen esto y esto de Chile, los chilenos les empiezan a explicar cómo es Chile, pero los peruanos quedan diciendo que no es verdad, y ahí se pican, se enojan y se ponen a pelear [E_Mujer2, Santiago].

Dichas implicancias a nivel de convivencia escolar traen expresiones de exclusión y asimetría de poder entre pares, que reflejan el peso que tienen las (re)construcciones heredadas y actuadas de lo nacional en el trato cotidiano. Ahí viene entonces la necesidad, a nivel institucional y social, de orientar acciones hacia el reconocimiento 
76 PENSAMIENTO NACIONALISTA-TERRITORIALIZADO Y PERCEPCIÓN DE "DESUBICAMIENTO" DEL INMIGRANTE: EL CAMINO HOSTIL DE LAS CONSTRUCCIONES DE IDENTIDADES CHILENAS EN LA CONVIVENCIA ESCOLAR - P. Roessler

de los actuales inmigrantes en Chile (Thayer et al., 2013). En el caso específico de las políticas públicas educativas, se vislumbran desafíos asociados con definir lineamientos claros para una planificación escolar que promueva tratos justos, protección de derechos, sin dejar de lado la urgente generación de condiciones educativas de calidad para todos. Estudios han señalado cómo las políticas escolares asimilacionistas producen situaciones de discriminación, por lo cual estas deben ir de la mano con la promoción de espacios en las escuelas para trabajar enfoques que consideren la diversidad cultural y de experiencias presentes en la comunidad educativa, dando pie a una educación que no acepte discriminación de ningún tipo, como parte de la formación de docentes y estudiantes (Jiménez et al., 2017; Riedemann y Stefoni, 2015; SJM, 2018).

Finalmente, el aislamiento, vulneración social y falta de privilegios desde donde forjan su yo-chileno en relación con un otroinmigrante por parte de los adolescentes participantes es algo a tomar en cuenta. Por ello, es esencial recalcar que no hablan de identidades chilenas desde el vacío, sino desde experiencias de exclusión, donde ni ellos mismos se sienten individuos integrados a la sociedad, ni verdaderos portadores de derecho. Sería interesante para futuros estudios centrarse en cómo el dislocado acceso a las estructuras de oportunidades en las que menores nativos se han socializado, dialoga con una sensación de mayor competencia por los recursos escasos, que puede potencialmente impactar en observar al inmigrante (y con ello a sus pares) como una amenaza que aumentaría dicha competencia. Lo mismo con las configuraciones de sentimientos truncos de ciudadanía en sociedades desiguales y segmentadas con pocos problemas y horizontes comunes, y el cómo ello podría hacer más difícil reconocer en otros, figuras de ejercicio de derechos, que ni ellos mismos han sentido en su crecimiento desde la no voz.

\section{Referencias}

Alguacil, J. (2006). Barrios desfavorecidos: diagnóstico de la situación española. Recuperado de http://www.fuhem.es/media/cdv/file/biblioteca/ Cohesi\%C3\%B3n\%20Social/ALGUACIL\%20G\%C3\%96MEZ,\%20 Julio,\%20Barrios\%20desfavorecidos.pdf 
Anderson, B. (1991). Imagined communities: Reflections on the origin and spread of nationalism (Second Edi). London: Verso.

Anderson, B. (1992). Long-distance nationalism: World capitalism and the rise of identity politics. The Wertheim Lecture, 1992. Amsterdam: Center for Asian Studies Amsterdam.

Appadurai, A. (2001). La modernidad desbordada: dimensiones culturales de la globalización. Buenos Aires: Ediciones Trilce.

Ayala, T. (2011). Ambrosio Rabanales y el español de Chile: una aproximación a los conceptos de norma y de chilenismo. Boletín de Filología, 46(2), 199-218. https://doi.org/10.4067/S0718-93032011000200008

Azócar, R. (2016). Desafíos y propuestas para contribuir al ejercicio de los derechos laborales de los trabajadores migrantes en Chile. Temas de la Agenda Pública, 11(90), 1-18. Recuperado de https://politicaspublicas. uc.cl/wp-content/uploads/2016/12/N\%C2\%B0-90-Derechoslaborales-de-los-migrantes.pdf

Bauböck, R. (Ed.). (2006). International migration, integration and social cohesion. IMISCOE Reports. Amsterdam: Amsterdam University Press.

Bravo, R. (2011). Inmigrantes en la escuela chilena: ciertas representaciones para ciertas políticas en educación. Revista Latinoamericana de Educación Inclusiva, 6(1), 39-52. Recuperado de https://dialnet.unirioja. es/descarga/articulo/4266684.pdf

Cabiedes, B., Bernales, M., McIntyre, A., Bersano, P., Gálvez, P., \& Azjraz, N. (2017). Escenario actual de la vida y salud de migrantes en la comuna de Santiago. Recuperado de http://repositorio. udd.cl/bitstream/handle/11447/1632/Reporte\%20Santiago. pdf? sequence $=8$ \& risAllowed $=y$

Canales, A. I. y Zlolniski, C. (2001). Comunidades transnacionales y migración en la era de la globalización. Notas de Población, 28(73), 221-252. https://doi.org/10.1007/s13398-014-0173-7.2

Cano, V. y Soffia, M. (2009). Los estudios sobre migración internacional en Chile: apuntes y comentarios para una agenda de investigación actualizada. Papeles de Población, 15(61), 129-167. Recuperado de http://www.redalyc.org/articulo.oa?id=11211806007

Castles, S. (2010). Understanding global migration: A social transformation perspective. Journal of Ethnic and Migration Studies, 36(10), 1565-1586. https://doi.org/10.1080/1369183x.2010.489381

Charmaz, K. (2006). Constructing grounded theory: A practical guide through qualitative analysis. Recuperado de http://www.sxf.uevora.pt/wpcontent/uploads/2013/03/Charmaz_2006.pdf 
78 PENSAMIENTO NACIONALISTA-TERRITORIALIZADO Y PERCEPCIÓN DE "DESUBICAMIENTO" DEL INMIGRANTE: EL CAMINO HOSTIL DE LAS CONSTRUCCIONES DE IDENTIDADES CHILENAS EN LA CONVIVENCIA ESCOLAR - P. Roessler

Chernilo, D. (2006). Social theory's methodological nationalism: Myth and reality. European Journal of Social Theory, 9(1), 5-22. https://doi.org/10.1177/1368431006060460

Connor, W. (1978). A nation is a nation, is a state, is an ethnic group, is a... Ethnic and Racial Studies, 1(4), 379-388.

https://doi.org/10.1080/01419870.1978.9993240

Dattwyler, R. H., Peterson, V. C. A., y Rivas, D. S. (2017). La espacialidad neoliberal de la producción de vivienda social en las áreas metropolitanas de Valparaíso y Santiago (1990-2014): ¿Hacia la construcción ideológica de un rostro humano? Cadernos Metrópole, 19(39), 513-535. https://doi.org/10.1590/2236-9996.2017-3907

Faist, T. (2004). The migration-security nexus. International migration and security before and after 9/11. Migration, Citizenship, Ethnos, 103-119. https://doi.org/10.1057/9781403984678_6

Fox, J. E. \& Miller-Idriss, C. (2008). Everyday nationhood. Ethnicities, 8(4), 536-563. https://doi.org/10.1177/1468796808088925

Fundación Superación de la Pobreza, FUSUPO. (2017). Calidad del empleo asalariado en población migrante de la Región Metropolitana. Serie Miradas País, 1. Recuperado de http://www.superacionpobreza.cl/wp-content/ uploads/2017/07/Estudio-Calidad-del-empleo-en-poblaci\%C3\%B3nmigrante-de-la-R.-M..pdf

Hale, C. R. (2005). Neoliberal multiculturalism. PoLAR: Political and Legal Anthropology Review, 28(1), 10-19.

https://doi.org/10.1525/pol.2005.28.1.10

Hobsbawm, E. J. (1990). Nations and nationalism since 1870: Programme, myth, reality. Cambridge: Cambridge University Press.

Jiménez, F., Aguilera, M., Valdés, R., y Hernández, M. (2017). Migración y escuela: análisis documental en torno a la incorporación de inmigrantes al sistema educativo chileno. Psicoperspectivas. Individuo y Sociedad, 16(1), 105-116.

https://doi.org/10.5027/psicoperspectivas-Voll6-Issuel-fulltext-940

Joiko, S. y Vásquez, A. (2016). Acceso y elección escolar de familias migrantes en Chile: no tuve problemas porque la escuela es abierta, porque acepta muchas nacionalidades. Calidad en la Educación, 45, 132-173. https://doi.org/10.4067/S0718-45652016000200005

Junta Nacional de Auxilio Escolar y Becas, Junaeb. (2016). Prioridades 2016 con IVE SINAE básica media y comunal [Base de datos]. Recuperado de https://www.junaeb.cl/ive 
Kaztman, R. (2001). Seducidos y abandonados: el aislamiento social de los pobres urbanos. Revista de la CEPAL, 75, 171-189. Recuperado de https://www.cepal.org/publicaciones/xml/6/19326/katzman.pdf

Larraín, J. (2010). Identidad chilena y el bicentenario. Estudios Públicos, 120. Recuperado de https://www.cepchile.cl/cep/site/artic/20160304/ asocfile/20160304095416/rev120_jlarrain.pdf

Mieles, M., Tonon, G., y Alvarado, S. (2012). Investigación cualitativa: el análisis temático para el tratamiento de la información desde el enfoque de la fenomenología social. Universitas Humanística, 74, 195-225. Recuperado de http://www.redalyc.org/pdf/791/79125420009.pdf_

Ministerio de Educación, Centro de Estudios (2018). Mapa del estudiantado extranjero en el sistema escolar chileno (2015-2017). Santiago, Chile Recuperado de https://www.mineduc.cl/wp-content/uploads/ sites/19/2018/05/MAPA_ESTUDIANTES_EXTRANJEROS_SISTEMA_ ESCOLAR_CHILENO_2015_2017.pdf

Olwig, K. \& Paerregaars, K. (2011). "Strangers" in the Nation. En K. Olwig $\&$ K. Paerregaars (Eds.), The Question of Integration: Immigration, Exclusion and the Danish Welfare State (pp. 1-29). Newcastle upon Tyne: Cambridge Scholars Publishing.

Oppenheimer, L. \& Barrett, M. (2011). National identity and ingroupoutgroup attitudes in children: The role of socio-historical settings. European Journal of Developmental Psychology, 8(1), 1-4.

https://doi.org/10.1080/17405629.2010.533948

Perry, R., Sibley, C. G., \& Duckitt, J. (2013). Dangerous and competitive worldviews: A meta-analysis of their associations with social dominance orientation and right-wing authoritarianism. Journal of Research in Personality, 47(1), 116-127. https://doi.org/10.1016/j.jrp.2012.10.004

Pozo, V. (2014). Percepción sociolingüística de los peruanos residentes en Chile acerca de su variedad del español en interacción con el español chileno. Boletín de Filología, 49(2), 237-256.

https://doi.org/10.4067/s0718-93032014000200011

Ramírez, J. y Álvarez, S. (2009). "Cruzando fronteras": una aproximación etnográfica a la migración clandestina ecuatoriana en tránsito hacia Estados Unidos. CONFLUENZE Revista Di Studi Iberoamericani, 1(1), 89-113. Recuperado de http://dialnet.unirioja.es/servlet/articulo?cod igo $=4800640$ \&orden $=1$ \&info $=$ link

Reyes, A. (2009). La escuela secundaria como espacio de construcción de identidades juveniles. Revista Mexicana de Investigación Educativa, 
80 PENSAMIENTO NACIONALISTA-TERRITORIALIZADO Y PERCEPCIÓN DE "DESUBICAMIENTO" DEL INMIGRANTE: EL CAMINO HOSTIL DE LAS CONSTRUCCIONES DE IDENTIDADES CHILENAS EN LA CONVIVENCIA ESCOLAR - P. Roessler

14(40), 147-174. Recuperado de http://search.ebscohost.com/login. aspx ?direct=true $\& \mathrm{db}=$ fua $\& \mathrm{AN}=43026249 \&$ lang=es\&site=ehost-live

Riedemann, A. y Stefoni, C. (2015). Sobre el racismo, su negación, y las consecuencias para una educación anti-racista en la enseñanza secundaria chilena. Polis. Revista Latinoamericana, 14(42), 191-216. https://doi.org/10.4067/s0718-65682015000300010

Rojas, D. (2012) Percepción y valoración de variedades geográficas del español de Chile entre hispanohablantes santiaguinos. Boletín de Filología, 47(1), 227-232. https://dx.doi.org/10.4067/S0718-93032012000100006

Roulston, K., deMarrais, K., \& Lewis, J. B. (2003). Learning to interview in the social sciences. Qualitative Inquiry, 9(4), 643-668. https://doi.org/10.1177/1077800403252736

Sirlopú, D., Melipillán, R., Sánchez, A., y Valdés, C. (2015). ¿Malos para aceptar la diversidad? Predictores socio-demográficos y psicológicos de las actitudes hacia el multiculturalismo en Chile. Psykhe, 24(2), 1-13. https://doi.org/10.7764/psykhe.24.2.714

Servicio Jesuita a Migrantes, SJM. (2018). Informe de sistematización del Programa Migración y Escuela (Documento de trabajo Nº1). Santiago, Chile: Autor.

Sistema Información General de Estudiantes, SIGE. (2016). Matrícula por estudiante año 2016. Recuperado de http://datos.mineduc.cl/ dashboards/19776/descarga-bases-de-datos-de-matricula-porestudiante/

Skey, M. (2009). The national in everyday life: A critical engagement with Michael Billigs thesis of banal nationalism. The Sociological Review, 57(2), 331-346. https://doi.org/10.1111/j.1467-954x.2009.01832.x

Stefoni, C. (2011). Perfil migratorio de Chile. Recuperado de http://priem.cl/ wp-content/uploads/2015/04/Stefoni_Perfil-Migratorio-de-Chile.pdf

Stefoni, C., Stang, F., y Riedemann, A. (2016). Educación e interculturalidad en Chile: un marco para el análisis. Estudios Internacionales, 185(185), 716-240. https://doi.org/10.5354/0719-3769.2016.44534

Thayer, L. E., Córdova, M. G., y Ávalos, B. (2013). Los límites del reconocimiento: migrantes latinoamericanos en la Región Metropolitana de Santiago de Chile. Perfiles Latinoamericanos, 21(42), 163-191. https://doi.org/10.18504/pl2142-163-2013

Tijoux, M. E. (2013). Niños(as) marcados por la inmigración peruana: estigma, sufrimientos, resistencias. Convergencia Revista de Ciencias Sociales, 61, 83-104. Recuperado de http://www.scielo.org.mx/scielo. php?script=sci_arttext ppid=S1405-14352013000100004 
Tijoux, M. E. (2014). El otro inmigrante "negro" y el nosotros chileno. Un lazo cotidiano pleno de significaciones. Boletín Onteaiken, 17, 1-15. Recuperado de http://onteaiken.com.ar/ver/boletin17/art-tijoux.pdf

Van Assche, J., Roets, A., Dhont, K., \& Van Hiel, A. (2014). Diversity and out-group attitudes in the Netherlands: The role of authoritarianism and social threat in the neighborhood. Journal of Ethnic and Migration Studies, 40(9), 1414-1430.

https://doi.org/10.1080/1369183X.2013.876895

Vigh, H. (2009). Wayward migration: On imagined futures and technological voids. Ethnos, 74(December 2011), 91-109.

https://doi.org/10.1080/00141840902751220

Wimmer, A. \& Glick Schiller, N. (2002). Methodological nationalism and beyond: nation-state building, migration and the social sciences. Global Networks, 2(4), 301-334. https://doi.org/10.1111/1471-0374.00043

Recibido: 24/01/2018

Aceptado: 12/07/2018 